\title{
KSHV and the pathogenesis of Kaposi sarcoma: listening to human biology and medicine
}

\author{
Don Ganem
}

Howard Hughes Medical Institute, G.W. Hooper Foundation, and Departments of Medicine and Microbiology, University of California, San Francisco.

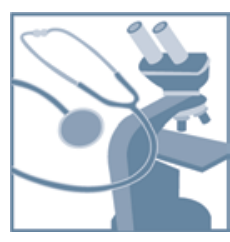

The linkage of Kaposi sarcoma (KS) to infection by a novel human herpesvirus (Kaposi sarcomaassociated herpesvirus [KSHV]) is one of the great successes of contemporary biomedical research and was achieved by using advanced genomic technologies in a manner informed by a nuanced understanding of epidemiology and clinical investigation. Ongoing efforts to understand the molecular mechanisms by which KSHV infection predisposes to KS continue to be powerfully influenced by insights emanating from the clinic. Here, recent developments in KS pathogenesis are reviewed, with particular emphasis on clinical, pathologic, and molecular observations that highlight the many differences between this process and tumorigenesis by other oncogenic viruses.

It is now 15 years since the discovery by Yuan Chang, Patrick Moore, and their colleagues (1) of DNA from a novel herpesvirus in biopsy specimens of human Kaposi sarcoma (KS). That virus, now called KS-associated herpesvirus (KSHV) or human herpesvirus 8 (HHV-8), has since been cloned (2-4) and sequenced $(2,5)$, grown in culture (6), and extensively studied in vitro. Epidemiologic studies $(7,8)$ provide strong evidence that infection by KSHV is required for $\mathrm{KS}$ tumorigenesis and further link the viral genome to at least two rare lymphoproliferative disorders: primary effusion lymphoma (PEL) and multicentric Castleman disease (MCD) (9). This review discusses the proposed mechanisms underlying the association of KSHV with KS, with particular emphasis on how they relate to the distinctive clinical and pathologic features of this unique human neoplasm.

\section{The pathobiology of KS}

It is a great misfortune that the term sarcoma was applied to the disease by Moritz Kaposi in the 19th century (10). The name implies a similarity of this entity to traditional mesenchymal tumors, but in fact the differences between KS and classical cancers outnumber their similarities. Such differences begin at the light microscope level: unlike most cancers, which are histologically monotonous clonal outgrowths of a single cell type, KS lesions display a remarkable diversity of cell types (11-14) whose proportions vary with the stage of the disease. The earliest recognizable foci of KS are the so-called patch lesions - these are not masses, but flat lesions in the dermis that display prominent numbers of inflammatory cells ( $\mathrm{T}$ and $\mathrm{B}$ cells, monocytes) and abundant neovascularity, features as characteristic of granulation tissue as of cancer. Already at this stage, angiogenesis is so profound that the gross lesions are red to the naked eye. This is an important fact: neovascularity in KS begins prior to establishment of a mass, in contrast to classical cancers, in which angiogenesis only begins after proliferation results in outgrowing the antecedent vascular supply (leading to selection for upregulation of proangiogenesis genes, termed the "angiogenic switch") (15). Patch lesions do con-

Conflict of interest: The author receives funds in return for service on the Scientific Advisory Boards for the Novartis Institute for Biomedical Research and 3V Biosciences Inc.

Citation for this article: J Clin Invest. 2010;120(4):939-949. doi:10.1172/JCI40567. tain the elongated, spindle-shaped cells that will come to dominate the lesion at its later stages, but these so-called spindle cells are only one of many elements at this stage. With time, dermal KS progresses to the plaque stage - in which the lesion is more indurated, often edematous, and more intensely red or even violaceous in color. As spindle cell proliferation continues, the lesions progress to the nodular stage, characterized by visible masses dominated by spindle cells but again accompanied by inflammatory cells and the continued elaboration of slit-like neovascular spaces (Figure 1). These new vessels, one of the histologic signatures of KS, are very abnormal and prone to leakage of fluid and extravasation of rbc, whose degeneration leads to phagocytosis and accumulation of hemosiderin-laden histiocytes. It is this extravasation of blood that gives the lesions their bruise-like purplish discoloration.

Because their proliferation leads to nodule formation, attention has long been focused on the spindle cell as the driver of KS pathogenesis - a notion that is in keeping with the fact that these cells are the principal target of KSHV infection in the lesion $(16,17)$ Spindle cells are clearly of endothelial origin, as they bear many markers of the endothelial lineage, including CD31, CD34, CD36, and factor $\mathrm{XIII}$, and reactivity with the endothelial cell-specific mAb PAL-E $(18,19)$. But the pattern of marker expression by spindle cells is also somewhat heterogeneous. A minority of spindle cells, for example, bear markers typical of smooth muscle cells - prompting some to suggest that spindle cells may derive from primitive mesenchymal precursors of vascular elements $(11,12)$. Some years ago, Beckstead et al. (20) proposed that spindle cells derive from lymphatic rather than vascular endothelium, a view supported by the fact that KS never arises in compartments lacking lymphatics (e.g., the central nervous system). This view gained currency when spindle cells were found to express lymphatic-specific markers (e.g., podoplanin and the lymphatic vessel hyaluronan receptor LYVE-1), as well as the signaling machinery involved in lymphangiogenesis (VEGF-C and its receptor VEGFR3) (21-23). However, transcriptional profiling studies (24-26) indicate that KSHV infection of endothelium alters the pattern of endothelial marker expression in a way that confounds lineage assignment. When vascular endothelial cells are infected in culture, they upregulate several markers of the lymphatic lineage $(25,26)$; conversely, infected lymphatic endothelial cells shift toward a more vascular-like transcript profile (24). While this reprogramming likely explains at least some of the pleiotropy 

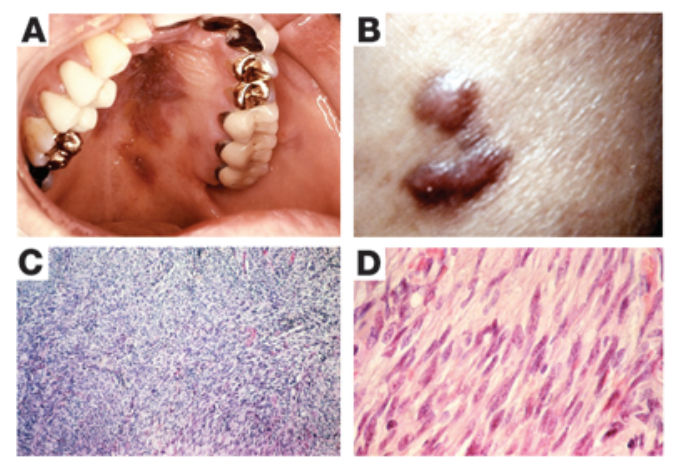

\section{Figure 1}

Kaposi sarcoma. (A) Gross lesions of KS on the palate of a patient with AIDS. (B) Nodular skin lesion seen in KS. (C) Histopathology of a nodular KS lesion, showing fascicles of elongated spindle cells and numerous slit-like neovascular spaces. (D) High-power image of KS spindle cells. All images reproduced from the CDC's open-access Public Health Image Library.

of marker expression in spindle cells, it also suggests that we may never be able to assign the exact endothelial lineage of spindle cells by marker studies alone.

Spindle cells are often referred to as the "malignant" cells of KS. But this designation is not strictly correct, and its continuing use largely reflects the absence of an alternative word to denote their centrality to KS pathogenesis. In fact, spindle cells have few properties in common with malignantly transformed cells - they usually $(27,28)$ (though not invariably; ref. 29) lack clonality, even in welldeveloped lesions. They are typically diploid - a sharp contrast to classical cancers, which are usually strikingly aneuploid. When put into culture, most spindle cells fail to display another malignant phenotype: reduced dependence on extracellular growth factors. In fact, KS spindle cells display the opposite phenotype - exaggerated dependence on such factors. To date, the only reproducible way to grow such cells in culture has been to incubate them in conditioned medium from activated T cells $(18,19,30)$, an environment laden with cytokines and growth factors. Moreover, cells prepared in this fashion do not display other experimental signatures of malignant transformation: they do not grow in soft agar and do not produce tumors in nude mice $(18,19,31)$.

Everything we know about the clinical behavior of KS also supports the distinction from traditional malignancy. KS occurs in two major forms - classical KS, which is unaffiliated with HIV infection, and AIDS-related KS. The two forms are histologically identical, and both are etiologically linked to antecedent KSHV infection (32). Classical KS is typically an indolent disorder that is generally confined to the skin, especially that of the legs. The lesions progress very slowly, such that many patients require no therapy - indeed, cases of spontaneous remission, though uncommon, have been well documented (33). When these lesions do progress, most such progression is local, with widespread dissemination being distinctly uncommon. Thus, classical KS is rarely life threatening (34). Although some traditional cancers can also be indolent, this relatively benign natural history is certainly compatible with the observation that spindle cells are not fully malignant by classical criteria.

AIDS-KS presents a more malign face - on the skin it can be widespread, involving large areas of the body surface, sometimes in a symmetrical fashion (35). Local nodularity and edema can be marked and can be profoundly disfiguring. Life-threatening complications arise from its propensity for visceral involvement, especially in the lungs (leading to respiratory failure) or the gastrointestinal tract (resulting in gastrointestinal bleeding). Interestingly, in AIDS$\mathrm{KS}$, the temporal pattern of occurrence of multifocal lesions is often not consistent with spread from a primary lesion, but rather suggests independent occurrences (multicentricity) (33). This inference has been supported by molecular analysis of KSHV genomes from KS lesions, which has affirmed that different lesions from the same patient often harbor genomes of differing terminal structure, suggesting they arose from independent infection events (28).

One other clinical aspect of KS is worth noting here - namely, its relationship to inflammatory states, both systemic and local. In the era prior to effective antiretroviral therapy, it was often noted that AIDS patients with stable KS who experienced a severe systemic infection would sometimes develop a florid worsening of KS during or after the infection. More telling still is the propensity of KS to occur at local sites of inflammation (e.g., surgical incisions or sites of prior zoster eruptions) (36-38). These observations suggest that an inflammatory microenvironment, which is always a part of KS histology, actually promotes the establishment or development of KS lesions - an idea that is strikingly concordant with the need for cytokine-rich media for the propagation of spindle cells in vitro.

From a pathogenetic viewpoint, it is helpful to think of KS as being composed of three parallel processes: proliferation (principally affecting spindle cells), inflammation, and angiogenesis. Unlike traditional cancer, which is predominantly a proliferative state driven by tumor cells that have achieved substantial autonomy and only later trigger inflammatory and angiogenic responses, $\mathrm{KS}$ is a disease in which all three processes participate simultaneously from its inception and are continuously necessary for the lesion to progress. A useful synthesis envisions that spindle cells produce proinflammatory and proangiogenic factors that recruit inflammatory cells and neovascular elements; these in turn provide growth factors and other substances necessary for spindle cell survival and proliferation $(19,39,40)$. Unlike in traditional cancers, no one component of this triad is truly autonomous. Although this is an attractive formulation, it has been difficult to test experimentally, in no small measure owing to the absence of suitable animal models of KS. Nonetheless, this paradigm rationalizes most of the cardinal clinical and experimental observations made to date.

\section{The etiologic role of $\mathrm{KSHV}$}

In the 1980s, the widespread occurrence of KS in AIDS patients initially suggested that HIV might be its proximate cause. But two facts soon put this idea to rest: (a) HIV proviral DNA was not present in the tumor; and (b) not all HIV-positive subjects were equally at risk of KS. KS risk was much greater in homosexual men with AIDS than in any other AIDS risk group (41). It soon became clear that sexual transmission of HIV was linked to much higher risk of KS than parenteral transmission of the virus, even though recipients in both cases became equally immunodeficient. This suggested that, in addition to HIV infection, a second agent linked to sexual activity must be involved - the search for which led Chang, Moore, et al. to KSHV (1).

The discovery of the KSHV genome allowed rapid development of both PCR tests for viral DNA and serologic tests for antiviral antibodies. This in turn made possible population-based studies 


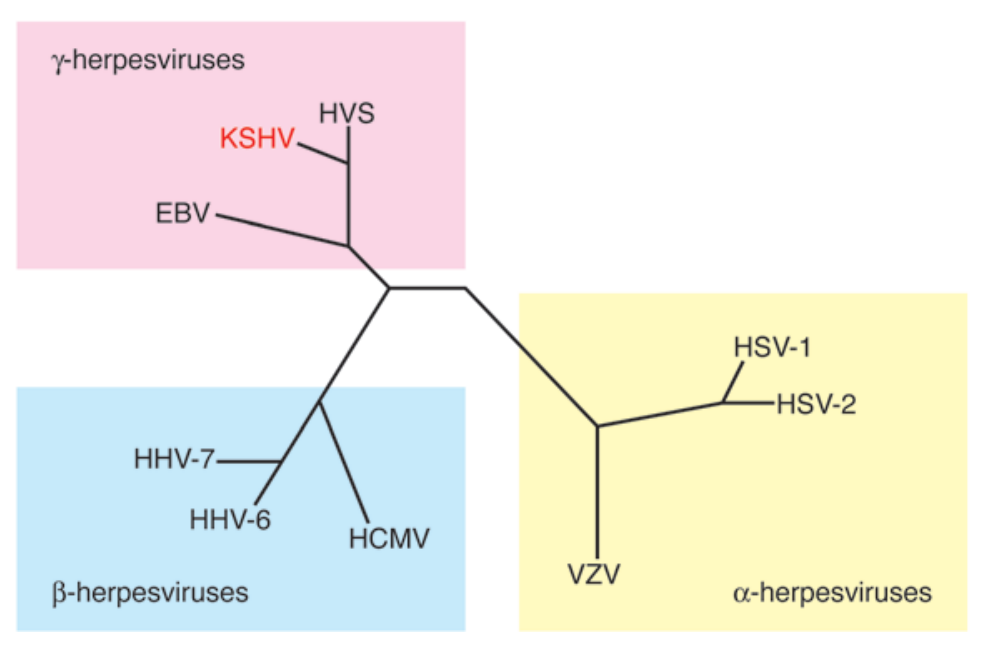

\section{Figure 2}

Phylogenetic tree of selected major herpesviruses. HSV, herpes simplex virus; VZV, varicella-zoster virus; HCMV, human cytomegalovirus; HHV, human herpesvirus; HVS, herpesvirus saimiri (a simian virus). Figure reproduced with permission from Journal of Virology (193). that soon delineated the key facts of KSHV epidemiology - all of which supported a central role for KSHV infection in KS development. The major pillars of this association have been reviewed elsewhere (8) and can be summarized as follows: (a) all KS lesions, whether HIV-positive or -negative, harbor KSHV DNA (42-44); (b) in KS tumors, KSHV infection specifically localizes to the spindle cells, the cell type whose proliferation is thought to drive KS histogenesis (16); (c) in any given locale, KSHV seroprevalence is high $(30 \%-60 \%)$ in AIDS risk groups in which KS is frequent and low (2\%-4\%) in groups in which it is rare (45-47); (d) globally, $\mathrm{KSHV}$ prevalence mirrors the distribution of classical KS - high $(15 \%-60 \%)$ in regions where classical KS is common (Southern Mediterranean and Africa) and low $(1 \%-5 \%)$ in regions where classical KS is rare (e.g., the United States) $(7,46)$; (e) KSHV infection precedes KS development (48) and prospectively predicts elevated KS risk (49); and (f) consonant with KS epidemiology, KSHV is sexually transmitted, with male homosexuals at especially high risk $(49,50)$. Taken together, these facts strongly imply that KSHV is the agent predicted by KS epidemiology and is necessary for KS development - KS is never observed in the absence of KSHV.

However, these facts also imply something equally important: that while necessary for KS development, KSHV infection is not sufficient for it. For example, although $1 \%-5 \%$ of the U.S. population is KSHV-seropositive, most of these individuals never develop overt KS. Population-based estimates suggest that even in endemic zones, only about 1 in 10,000 infected subjects will develop classical KS (51-54). Clearly, additional events are necessary to trigger KS development. The identity of those additional events in classical KS is unknown and represents one of the great unsolved problems of KS research. In AIDS-KS, however, the second hit is clearly HIV. The magnitude of HIV's contribution to KS risk is immense $-50 \%$ of dually infected men who receive no effective treatment for either HIV or KSHV will develop KS in a ten-year period (49). Further evidence that HIV infection is a central cofactor comes from the greater than $90 \%$ decline in incident KS in the United States and Europe in the era of highly active antiretroviral therapy $(\operatorname{HAART})(55,56)$. Moreover, established KS frequently goes into remission when AIDS-KS patients are treated with HAART (57-59). Given this, it seems a bit diminutive to refer to HIV as a mere "cofactor" - but formally speaking, that is its role.

The exact mechanisms by which HIV amplifies KS risk during $\mathrm{KSHV}$ infection remain contentious. Certainly the immune defi- ciency state of advanced HIV disease is a major contributor to risk - a fact supported by the existence of transplant-associated KS, which arises from KSHV infection in the context of iatrogenic immune suppression (60). But there are other, more direct possibilities. Laboratory experiments indicate that in certain settings, HIV infection can augment KSHV replication, in both cell-autonomous $(61,62)$ and paracrine (63) fashions. However, the frequency of dual infection of cells in vivo by HIV and KSHV is very low (17), making a major contribution from cell-autonomous pathways unlikely. Paracrine pathways provide a more attractive mechanistic connection. Mercader et al. (63) found that cytokines, especially oncostatin $\mathrm{M}$ and IFN- $\gamma$, produced by HIV-infected cells can trigger lytic KSHV reactivation, which could foster dissemination of KSHV infection, thereby predisposing to KS. Barillari and Ensoli have proposed a different connection, pointing out that soluble HIV Tat protein can serve as a growth factor for cultured KS spindle cells in vitro (64). Sadly, absent a reliable animal model of KS, decisive in vivo tests of any of these ideas will be difficult.

\section{KSHV virology: a primer}

As found in the virion, KSHV DNA is a linear duplex of approximately $165 \mathrm{~kb} ; 140 \mathrm{~kb}$ of this DNA contains coding information, flanked on either side by tandem (terminal) repeats of $1.4 \mathrm{~kb}$ of highly GC-rich noncoding sequences $(65,66)$. In infected cell nuclei, the genome circularizes to form a covalently closed circular episome. The complete nucleotide sequence (2) of KSHV predicts the existence of at least 87 ORFs.

Tropism. Phylogenetic analysis reveals that KSHV is a member of the lymphotropic (or $\gamma$ ) herpesvirus subfamily, whose prototype human member is EBV (Figure 2). Like EBV, KSHV's primary target cell is the B cell, and in healthy seropositive hosts viral DNA is principally found in this compartment (67). Evidence that KSHV also infects endothelium in vivo derives chiefly from the presence of viral DNA in KS spindle cells, and also in some cells lining the aberrant slit-like vessels of KS lesions $(68,69)$. One study has also sighted KSHV markers within monocytes infiltrating KS lesions (70). But overall, it bears emphasis that KSHV's tropism in vivo is quite restricted. This is in sharp contrast to its behavior in vitro: KSHV will efficiently infect a wide variety of adherent human cells in culture, including epithelial cells, fibroblasts, and keratinocytes, as well as endothelial cells (71-73). Paradoxically, most established human $\mathrm{B}$ cell lines are not infectible, though recent studies show 


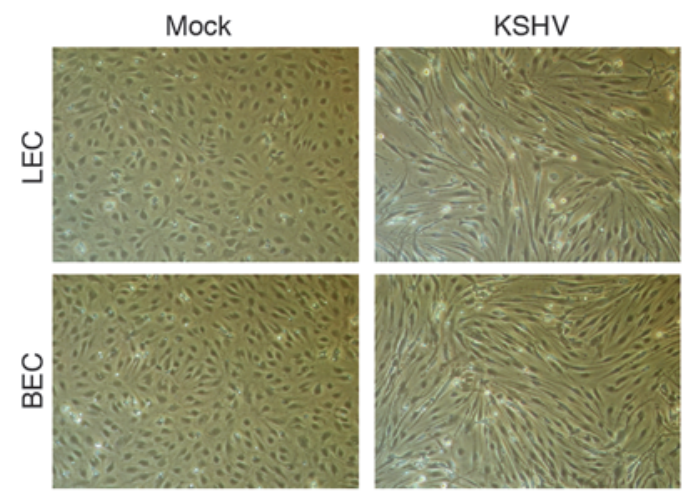

Figure 3

Phenotypic effect of latent KSHV infection in primary endothelial cells in culture. BEC, blood vessel endothelial cell; LEC, Iymphatic endothelial cell. Left column: mock infection; right column: KSHV infection. One week after infection, cells were photographed under brightfield imaging (original magnification, $\times 40$ ).

that primary peripheral blood B cells can be infected in vitro if they are first activated by CD40 ligand and IL-4 (74). Why cell types that can be so readily infected in vitro are refractory in vivo is unknown, but this fact needs to be kept in mind when evaluating claims about KSHV tropism based solely on studies in culture.

Replication cycles. Like all herpesviruses, KSHV can express its genes in one of two alternative genetic programs, depending upon the circumstances of infection. The first of these, latency, is a state in which viral gene expression is sharply restricted, with only a handful of viral genes being stably expressed. In latent infection, the incoming linear viral genome circularizes in the nucleus, and the resulting large episome is autonomously maintained there, usually at low-moderate copy number. Because most viral genes are not expressed, there is no cytotoxicity and no virus is released. In KSHV, as in EBV, latency is the default pathway, at least in culture. In most established cell lines in culture, the latent infection that follows KSHV exposure displays no evident phenotype (73). Similarly, primary B cells infected with KSHV become neither immortalized nor transformed $(74,75)$. This is in striking contrast to infection by EBV, whose latency program is powerfully immortalizing in B cells (76). However, there is one cell type whose in vitro infection by KSHV does yield phenotypic consequences - primary endothelial cells (Figure 3). When such cells are exposed to KSHV, striking morphologic changes occur, dominated by a rearrangement of the actin cytoskeleton that produces an elongated morphology strongly reminiscent of that of the spindle cell (77, 78). However, even these cells are not immortalized, do not grow in soft agar, and do not form tumors in nude mice - although they do display heightened resistance to induction of apoptosis by growth factor withdrawal (79).

Importantly, latency is not irreversible. Because the full complement of viral DNA is retained in the nucleus, under the appropriate circumstances the second program of viral gene expression, lytic replication, can be activated. In this program, expression of virtually all viral genes is activated, in a temporally regulated cascade; infectious viral progeny are produced, and the infected cell is killed $(6,80)$. The physiologic signals that trigger lytic KSHV reactivation in vivo are unknown. We do know that periodic "spontaneous" reactivation from latency occurs regularly, both in cell culture (6) and in vivo $(72,81,82)$. In the human host, the principal site of lytic virus replication is the oropharynx, most likely in B cells of tonsillar or other pharyngeal lymphoid tissue, though growth in pharyngeal epithelium is another possibility (83). Careful clinical studies show that shedding of KSHV virions, reflecting periodic bouts of lytic reactivation, is intermittent and generally asymptomatic $(81,82)$. This biology underlies much of the epidemiology of KSHV, which is presumed to be driven by mucosal exposure to salivary virus, both in sexual transmission among adults (49) and in horizontal spread of virus among prepubertal children in the endemic zones of Africa and the Mediterranean basin (7).

\section{How does KSHV infection predispose to KS?}

For the virologist, this question reduces to: what KSHV genes are expressed in the tumor, and how do they act? Although this may seem a straightforward question, it is complicated by the fact that herpesviral genomes can be expressed via either latent or lytic programs. Both programs are on display in KS tumors (17), especially those of patients with advanced HIV-induced immune deficiency. Most spindle cells in an advanced KS tumor are latently infected, but a small minority of cells express lytic markers $(17,68,69,84)$.

The bimodal expression program of the KSHV genome requires that, when considering the pathogenetic roles of viral genes, careful attention be paid to which program of viral gene expression governs transcription of that gene; failure to do so can invite misinterpretation. For example, early findings that viral genes such as ORF-K9 (encoding an IRF-1 homolog; ref. 85) or ORF-74 (encoding a viral GPCR; ref. 86) could immortalize transfected mouse fibroblasts led to suggestions that they might drive proliferation in KS (85-88). However, the subsequent discovery that these genes appear to be expressed only during lytic growth $(39,89-91)$ rendered such roles implausible, since lytically infected cells invariably die. This is not to say that lytic genes can play no role in KS pathogenesis - in fact, considerable evidence is accumulating that they do (see Lytic genes and $K S$ development, below). But because of the cell death induced by lytic replication, any contribution of lytic products to KS must be non-cell autonomous. Because of considerations such as these, in the following sections, the potential oncogenic contributions of latent- and lytic-cycle genes are discussed separately.

Latent viral genes. The best characterized latent genes constitute a major latency locus that is transcribed in all latently infected cells (Figure 4). This region includes several ORFs, encoding the proteins latency-associated nuclear antigen (LANA), viral cyclin (v-cyclin), v-Flice-inhibitory protein (v-FLIP), and kaposins A, $\mathrm{B}$, and $\mathrm{C}$. The first three genes are under the control of a single promoter (the LANA promoter, or LTc), which generates a series of coterminal mRNAs via differential splicing (92-94). A second promoter (the kaposin promoter, or LTd) encodes a spliced transcript encoding the kaposins (95-97) and can also generate a bicistronic RNA for v-cyclin and v-FLIP. This promoter also governs the expression of 12 pre-miRNAs (Figure 4), which can be processed to yield a total of 18 mature miRNAs (98-102). All of these latent products have been found to be expressed in KS spindle cells as well as PEL cells (103-105). A second locus, expressed in latent PEL cells, encodes the v-IRF3 (or LANA-2) protein, a member of the IRF superfamily that dominantly inhibits IFN induction (106). This gene is expressed only in PEL cells and not in KS cells and for this reason will not be further considered here. In this section, the functions of selected latent products with known or suspected links to KS pathogenesis are highlighted. 


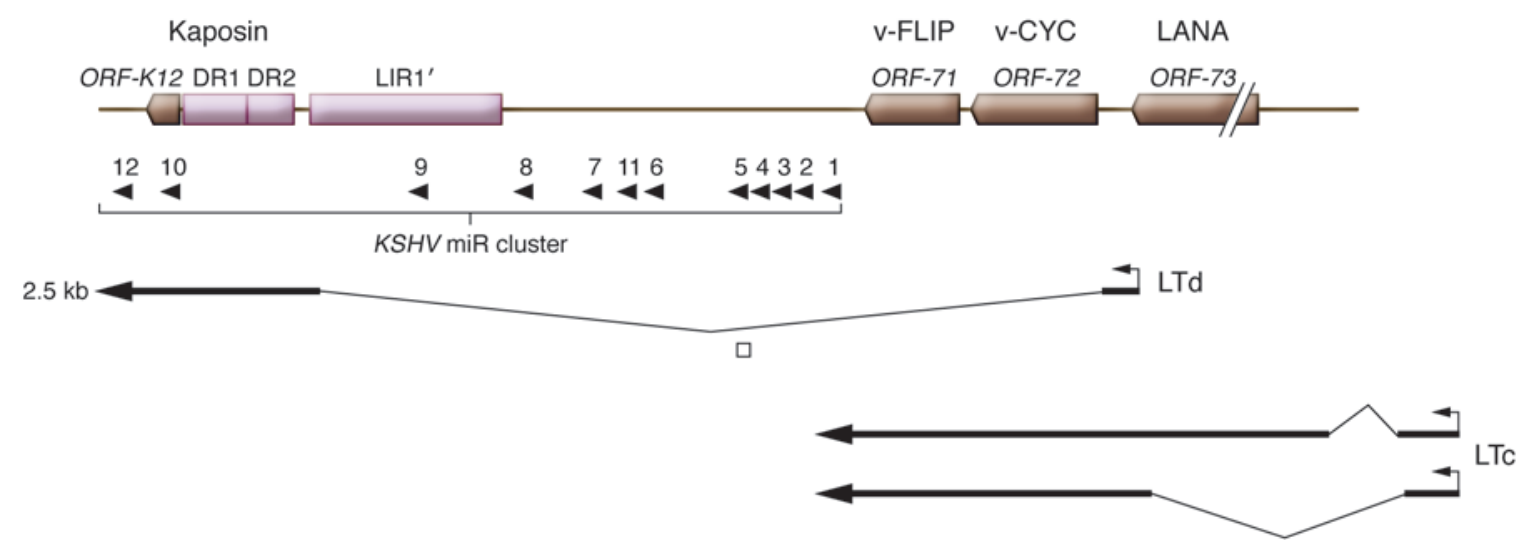

Figure 4

Structure of transcripts from the major latency locus of KSHV. Top panel: Disposition of ORFs in the latency cluster. ORF-73 encodes LANA; ORF-72 encodes v-cyclin ( $\mathrm{V}-\mathrm{CYC}$ ); ORF-71 encodes V-FLIP; ORF-K12 encodes kaposin A; DRs 1 and 2 encode direct repeats in which translation of kaposins $B$ and $C$ initiate. LIR, long interspersed repeats. Middle panel: KSHV microRNA (miR) cluster, with pre-miRNAs indicated by arrowheads. Bottom panels: Structures of transcripts directed by the kaposin (or LTd) promoter and by the LANA (or LTC) promoter. Figure modified with permission from RNA (101).

The best understood of the latency proteins is LANA, whose principal role in viral replication is to promote replication of the latent viral episome - a property mediated by its ability to bind specifically to sequences within the terminal repeats of the viral genome (107-112). Its ability to also bind cellular histones H2A and H2B (113) (and possibly other chromosomal proteins; ref. 114) also allows it to tether viral genomes to mitotic chromosomes, assuring their segregation to daughter cells in mitosis (107, $109,113,115)$. Thus, LANA expression is necessary for persistent infection, without which KS will not develop. However, it is to be emphasized that LANA's support of genomic maintenance is inefficient - rapidly dividing cultured cells often lose the KSHV episome within 5-10 cell doublings (unless there is a genetic selection for episome maintenance) (116). This explains why most spindle cell lines derived from KS tumors lack the viral genome after outgrowth from the primary tumor (117-119). Interestingly, some viral genomes can undergo epigenetic changes that stabilize the latent genome, allowing persistence in the absence of selection (116) - such changes appear to be the rule in PEL but are uncommon in KS. The relative instability of KSHV genomes in KS has important implications for tumorigenesis. If KS lesion development requires viral persistence, and if episome maintenance is inefficient in spindle cells, then it might be predicted that progression of a KS lesion would require concomitant lytic replication to allow de novo infection of cells to replace infected cells lost via episome segregation. In fact, strong clinical evidence (120) supports the idea that lytic KSHV replication is also important for KS progression (see Lytic genes and KS development, below).

LANA very likely makes additional, more direct biochemical contributions to tumorigenesis, since it has also been shown to bind and (partially) inhibit the cellular tumor suppressor genes p53 (121) and $R b$ (122). It also can posttranslationally upregulate expression of host $\beta$-catenin (123), which activates a proliferative gene expression program that includes the protooncogenes c-myc, c-jun, and cyclin D. Together, these activities could inhibit apoptosis and thus extend spindle cell survival, and also stimulate spindle cell proliferation.

The discovery that KSHV encodes a functional cyclin D homolog (termed v-cyclin) (124) in latency provoked great interest, given the known roles of this family of proteins in the regulation of the cell cycle (125) and the fact that v-cyclin makes cyclin-dependent kinase $6(\mathrm{cdk} 6)$ more refractory to the inhibitory effects of $\mathrm{cdk}$ inhibitors such as p27 (126-128). However, it has been extremely difficult to rigorously identify its pathogenetic role in KS, since isolated expression of $\mathrm{v}$-cyclin in cells tends to promote replicative stress and DNA damage responses, leading to growth arrest and, in some contexts, apoptosis $(129,130)$.

The role of the adjacent v-FLIP gene, which encodes a homolog of known cellular FLIPs, is much better understood. Cellular FLIPs are known to inhibit Fas-mediated caspase activation, promoting resistance to Fas-mediated apoptosis (131). Although it has been alleged that the KSHV v-FLIP protein shares this activity (132, 133), most current evidence suggests it does not (134). But there is no question that KSHV v-FLIP is a potent antiapoptotic effector; for example, siRNA-mediated inactivation of $\mathrm{v}$-FLIP provokes apoptosis in PEL cells $(135,136)$. v-FLIP's prosurvival activity is linked to its ability to activate the transcription factor NF-кB (137, 138). NF- $\kappa B$ is maintained in cells in an inactive cytoplasmic form, bound to the inhibitor IкB. v-FLIP binds and activates the $\gamma$ subunit of IкB kinase (IKK) (139-141). The resulting IкB phosphorylation displaces $\mathrm{I} \kappa \mathrm{B}$ from NF- $\mathrm{KB}$, releasing the active transcription factor to the nucleus, where it activates a large panel of antiapoptotic and proinflammatory genes. Expression of v-FLIP in spindle cells thus not only can extend their lifespan $(142,143)$ but also can explain, at least in part, the inflammatory phenotype of KS lesions. NF- $\kappa$ B activation by v-FLIP expression in endothelial cells has also been linked to a third phenotype relevant to KS - the dramatic rearrangement of the cytoskeleton that gives the cells their characteristic spindle shape $(78,144)$. Finally, in many $(145)$ (but not all; ref. 146) cell contexts, activation of NF-кB by v-FLIP opposes lytic reactivation, thereby stabilizing latency.

A few kilobases away from the v-FLIP gene is the kaposin locus, a complex and poorly understood region that encodes at least 3 proteins, kaposins A, B, and C (147). Kaposin A is a tiny (60-aa) transmembrane protein whose overexpression in fibroblasts can lead (albeit inefficiently) to their transformation in vitro, suggesting that the molecule can stimulate signaling pathways linked 
to growth deregulation (148). How it does so is unclear but may relate to its ability to bind cytohesin-1 (149), an exchange factor for ADP ribosylation factor (ARF) family GTPases, key regulators of vesicular trafficking and of the dynamics of the actin cytoskeleton (150). Kaposin B is a scaffolding protein, one of whose functions is to activate the p38 MAPK signaling pathway, via direct interaction with the kinase MK2, a key p38 substrate (151). An important consequence of this is the stabilization of cytokine and growth factor mRNAs, by inhibition of a degradative pathway that targets AU-rich elements (AREs) in their $3^{\prime}$ untranslated regions (UTRs) (151). Thus, kaposin B is a second latent gene product that promotes the proinflammatory microenvironment so characteristic of KS lesions - and upon which they appear to depend.

The kaposin transcription unit also encodes 12 pre-miRNAs (refs. 98-101; Figure 4). As noted above, these pre-miRNAs can engender 18 mature miRNAs at last count (102). Some of these miRNAs appear to function as modulators of the latent-lytic switch, which they can influence in either a negative (152) or positive (153) direction. Both host and viral mRNAs are targeted by the KSHV miRNAs, but identification of these targets is still is in its infancy. One miRNA targets the expression of the viral RTA protein (152), the master regulator of lytic induction. As to host targets, several KSHV miRNAs have been found to downregulate thrombospondin, a known antagonist of angiogenesis - thus, they could contribute to the neovascular phenotype of KS (154). One KSHV miRNA, miRK11, shares seed sequence identity with a lymphoid-specific host miRNA (miR155) whose targets affect B cell differentiation $(155,156)$; this miRNA may play roles in $\mathrm{B}$ cell infection and possibly in PEL development. Its participation in KS pathogenesis is unknown, but very recent data indicate it could play a role in the regulation of endothelial differentiation via regulation of the MAF transcription factor (157).

Finally, very recent evidence suggests that a small number of genes outside the major latency locus may also be expressed in latency (158). Chief among these is ORF-K1, a transmembrane signaling molecule whose activity mimics signaling via the B cell antigen receptor (159). These findings may be important in KS pathogenesis, since it has been shown that $\mathrm{K} 1$ overexpression in primary endothelial cells can substantially extend their lifespan (160).

Lytic genes and KS development. In other oncogenic herpesviruses, the lytic cycle has not generally been considered to play a prominent role in tumorigenesis, since it causes cell death. In most formulations, its only (imputed) role is to allow spread of virus throughout the body early in infection, putting many cells into latency. From that point on, according to this view, the enhanced survival and proliferation engendered by latency promotes mutations, replicative errors, and chromosomal rearrangements that put the cells on their long mutational march to cancer. But does this model apply to KSHV and KS? Certainly the weak phenotype of KSHV latency provides ample grounds for wondering whether latency in this virus has the capacity to do all the heavy lifting of tumorigenesis. But much stronger evidence implicating the lytic cycle in KS has come from clinical study of the role of ganciclovir in AIDS patients (who were being treated with the drug for CMV retinitis). This revealed that patients receiving systemic ganciclovir had a 5- to 8-fold decline in incident KS during the follow-up period (120). Since these end-stage AIDS patients had certainly carried HIV and KSHV for many years, and since ganciclovir specifically blocks lytic replication and has no effect on latency, the results strongly suggest that lytic KSHV replication is continu- ously necessary throughout the long natural history of infection in order for KS to develop.

Why might this be so? There could be three (non-mutually exclusive) reasons. First, if KSHV latency is not immortalizing $(73-75,77)$, then even if a latently infected cell's lifespan is extended (79), sooner or later that cell will die, and the only way it can be replaced is for another, uninfected cell to be recruited to latency by infection with a virus produced by lytic replication. Second, if latency is unstable (116), then proliferating infected cells will ultimately segregate uninfected daughter cells, and optimal growth of an infected lesion will be impaired without de novo infection of more cells by lytically produced virions. A third model harkens back to the notion that KS tumors comprise a triad of proliferation, inflammation, and angiogenesis. It was noted above that lytic infection of proliferating cells will kill them. However, the majority of the inflammatory and neovascular elements in a KS tumor are composed of uninfected cells. If a small percentage of $\mathrm{KS}$ cells are in the lytic cycle, and if these cells can secrete proinflammatory or proangiogenic factors, then they could influence the inflammatory and vascular components of the lesion even though their survival is only transient.

Many genes in the lytic cycle have been proposed as candidates for contributing to such paracrine signaling. First, the virus itself encodes several secreted proteins that are active signaling molecules, some of which are clearly proinflammatory. Chief among these is v-IL-6, a homolog of cellular IL- 6 that can signal by binding directly to gp130 without interaction with the high-affinity IL-6 receptor (161). v-IL-6 signaling upregulates an angiogenic program (162), especially the production of angiopoietin 2 (163) - a protein that is known to promote vascular remodeling and enhance vascular permeability. The latter feature is of great interest, since local edema is a prominent clinical feature of KS lesions. Three CC chemokine homologs are also encoded by KSHV (164). These chemokines have important effects on lymphocytes - some are chemotactic for Th2 cells $(165,166)$, contributing to immune evasion by promoting Th2 polarization of the microenvironment (167). But viral chemokines can also affect the microvasculature by promoting endothelial cell migration (168), upregulating VEGF expression (169), and stimulating angiogenesis $(164,170)$. Recent studies (171) reveal that the viral chemokine ligands v-CCL1 and $\mathrm{v}$-CCL2 can promote the survival of primary endothelial cells by inhibiting Bim expression and thereby blocking apoptosis.

Beyond these secreted proteins, the KSHV lytic program also includes several transmembrane signaling proteins that can induce the expression of host genes with proinflammatory or proangiogenic potential. Chief among these is the viral GPCR (v-GPCR) encoded by ORF-74. As previously noted, this gene encodes a constitutively active signaling molecule with powerful effects on gene expression (86). Among the host angiogenic factors whose expression is induced by v-GPCR signaling are: VEGF $(87,172)$, a potent proangiogenic factor whose other activity is to promote vascular permeability; angiogenin (173); and angiopoietin 2 (163). KS lesions express all 3 factors, and lytic infection is associated with strong upregulation of angiopoietin 2 (174, $175)$. And v-GPCR is not the only gene expressed in lytic infection that can upregulate VEGF; ORF-K1 expression, which is strongly upregulated during lytic infection $(66,176)$, also has this activity $(177,178)$. Other lytic viral proteins can upregulate inflammatory signaling by the host. For example, the product of ORF-K15 is a polytopic transmembrane protein whose cytosolic tail can under- 
go tyrosine phosphorylation, leading to TRAF3 recruitment and NF- $\kappa \mathrm{B}$ activation. The net result is activation of a large program of cytokine and chemokine expression $(179,180)$.

All of the above data were generated by transfection of individual lytic genes into uninfected cells in culture. However, a caveat must be made before these results can be extrapolated to the setting of viral infection: during authentic infection, starting midway through the lytic cycle (roughly contemporaneously with the expression of v-GPCR and the ORF-K15 protein), KSHV imposes a strong block on host gene expression. This block is due to a global acceleration of host mRNA decay, mediated by a single KSHV gene called SOX (181). About $80 \%$ of host genes are subject to SOX-mediated turnover and display variable but often profound decreases in mRNA abundance (175) The steady-state levels of another $15 \%-18 \%$ of mRNAs are unchanged after infection, while $2 \%$ of the host transcriptome is actually upregulated during lytic growth, reflecting escape from SOX-mediated regulation (175). (Interestingly, this $2 \%$ includes gene products such as IL-6 and angiopoietin 2.) Notably, VEGF mRNA is subject to SOX-mediated decay. However, modest increases in VEGF mRNA are observed early in the lytic cycle (175), before SOX-mediated shutoff is established, so translation of this message could lead to modest rises in VEGF in the microenvironment of lytically infected cells. The same is true of other SOX-regulated host transcripts - expression in the brief window of time prior to SOX accumulation could allow for modest accumulation of their translation products. Thus, although transfection of individual KSHV signaling genes in cultured cells usually overstates the magnitude of the induction they can achieve in vivo, it does still provide useful qualitative hints about this process.

Recently, an interesting small animal model of KS pathogenesis has been presented by Mesri and colleagues that has further supported the likely role of lytic cycle genes in KS generation (182). In this system, murine bone marrow-derived endothelial cells were transfected with a bacmid bearing the entire KSHV genome. After selection for a linked drug-resistance marker, cell lines emerged in vitro that harbored the complete KSHV genome. These cells had several properties reminiscent of KS spindle cells, including elongated morphology; inability to grow in soft agar; upregulation of VEGF, VEGFR2, and angiopoietin 2; and instability of the viral episome (i.e., when drug selection was removed, the episome was rapidly lost). Implantation of these cells into nude mice produced vascularized, sarcoma-like lesions populated by spindle-shaped cells. Importantly, these lesions depended upon the presence of the viral genome: segregants that had lost the genome were incapable of producing the tumors upon implantation. This is an appealing set of properties and clearly reinforces the connection between viral gene expression and spindle cell shape, survival, and induction of neoangiogenesis. It is the first animal model that clearly reproduces the selective advantage conferred by the presence of the viral genome in vivo in the absence of overt transformation in vitro - a central feature of the human biology of KS.

However, there are indications that the model does not faithfully reproduce all the features of authentic KS. Expression profiling reveals that a large number of lytic KSHV genes are being expressed at elevated levels in these cells after implantation in the animal host (182). Even though many lytic genes are turned on (and are on in a large number of cells), no cytopathic effect is present and no viral progeny is being produced. It appears that a large population of these mouse cells is undergoing a kind of abortive infection not typical of what is seen in human KS. Given the rather promiscuous nature of gene expression in this model, and the large number of lytic genes that can trigger proangiogenic or proinflammatory changes, there are legitimate questions as to whether the model will be an accurate guide to the subset of viral genes that is actually responsible for KS development in human cells. Despite these caveats, the system is a substantial advance and is highly consistent with the idea that lytic gene expression contributes to the KS phenotype.

\section{KS clinical investigation: the gift that keeps on giving}

While progress in the last decade on the molecular and cellular biology of KSHV infection has been explosive, clinical investigation has not stood still either. In fact, it has continued to provide provocative new observations that reshape our thinking about KSHV pathogenesis - and even suggest new directions for laboratory investigation. For example, examination of patients with AIDS-KS who undergo successful antiretroviral therapy reveals that as $\mathrm{CD}^{+}$ $\mathrm{T}$ cell counts rise and immune function is restored, preexisting KS lesions often transiently get worse, with more swelling, induration, and vascularity $(183,184)$. With time, most such lesions will either stabilize or resolve, but on occasion the process is severe enough to warrant chemotherapy $(185,186)$. This transient worsening of KS during the period of immunologic recovery (termed immune reconstitution inflammatory syndrome [IRIS]) is powerful testament to the role of inflammation in KS pathogenesis. Studies of cytokine and chemokine expression in KS-IRIS lesions are currently underway in an effort to understand the nature of the signals that might promote KS; other efforts center on determining the nature of innate and adaptive immune responses that ultimately lead to resolution of KS in this context. It will also be of interest to see whether different patterns of viral gene expression are induced during the transient worsening.

The study of transplantation-related KS is also advancing our understanding of this disease. Traditionally, post-transplantation $\mathrm{KS}$ is treated with withdrawal or reduction of immunosuppressive drugs; generally, KS can be controlled by this maneuver, but injury to (or loss of) the transplanted organ is often the result (60). In an effort to improve the outcome of post-transplantation KS, clinicians have recently tried substituting rapamycin (sirolimus) for the calcineurin inhibitors cyclosporine or tacrolimus after the appearance of a KS lesion (187). Rapamycin is not a calcineurin inhibitor; it binds the 12-kDa protein FK506-binding protein 1A (FKBP12), and the resulting complex binds the mammalian target of rapamycin (mTOR), thereby disrupting the function of one of the known mTOR signaling complexes, mTOR complex 1 (mTORC1). Signaling via mTORC1 promotes enhanced translation and cell proliferation (188). (Note: Rapamycin likely also affects signaling via a second mTOR complex, mTORC2, at higher drug concentrations.) Rapamycin is also an immunosuppressant, acting to impair $\mathrm{T}$ cell proliferation in response to IL-2, but is less potent than the calcineurin inhibitors, which block IL-2 production by activated T cells.

The clinical results of rapamycin treatment of transplant-related KS are dramatic: in the largest series published to date, 15 of 15 patients responded with complete clinical remission of KS, all the while retaining functioning allografts (187). These results have been independently replicated (189), though not all centers report equally high response rates (190). Even allowing for variability in response rates, this is a great advance in $\mathrm{KS}$ management. But it also poses an important biological question: is the result solely due to 
lessened immunosuppression, or does inhibition of mTOR signaling have direct antitumor effects? There is reason to believe that the latter might play a role: studies of both PEL cells and KSHV-infected endothelial cells have shown activation of PI3K and Akt phosphorylation $(191,192)$, both of which are events that occur upstream of mTORC1, the principal target of rapamycin action. Thus, viral infection may turn on the mTORC1 pathway. Rapamycin has been shown to induce growth arrest in many PEL cell lines (and apoptosis in a subset of them) (191), suggesting that this activation is functionally important; experiments are ongoing to determine the drug's effects in KSHV-infected endothelial cells. But perhaps the most direct and accurate way to gauge rapamycin's intrinsic anti-KS activity will be a clinical trial of the drug in classical (HIV-negative) KS patients, since they have no overt immune deficiency.

\section{Coda}

The pace of discovery in KS pathogenesis in the 15 years since the first sighting of the KSHV viral genome can only be described as breathtaking. Our understanding of the molecular basis of viral replication and gene expression has generated new hypotheses about the pathogenetic events that lead to this remarkable neoplasm. Everything we learn about replication from experimental systems, however, should be interpreted in the context of the human biology of KSHV. Most of the phenotypes of KSHV infection in cultured cells are subtle and not obviously informative about how KS evolves in vivo. Conversely, many of the phenotypes observed for individual KSHV genes overexpressed in transfected cells are more dramatic than those of KS itself and therefore invite misinterpretation. Such interpretive errors can be avoided only by rigorous comparison of each result with what is known of the pathology and clinical behavior of KS. Continued close attention to how experimental results square with the picture emerging from ongoing clinical investigations promises to make the next 15 years even more illuminating than the last.

Address correspondence to: Don Ganem, University of California, 513 Parnassus Ave., San Francisco, CA, 91413. Phone: 415.476.2826; Fax: 415.476.0939; E-mail: ganem@cgl.ucsf.edu.
1. Chang Y, et al. Identification of herpesvirus-like DNA sequences in AIDS-associated Kaposi's sarcoma. Science. 1994;266(5192):1865-1869.

2. Russo JJ, et al. Nucleotide sequence of the Kaposi sarcoma-associated herpesvirus (HHV8). Proc Natl Acad Sci U S A. 1996;93(25):14862-14867.

3. Zhong W, Wang H, Herndier B, Ganem D. Restricted expression of Kaposi sarcoma-associated herpesvirus (human herpesvirus 8) genes in Kaposi sarcoma. Proc Natl Acad Sci U S A. 1996;93(13):6641-6646.

4. Nicholas J, et al. Kaposi's sarcoma-associated human herpesvirus- 8 encodes homologues of macrophage inflammatory protein- 1 and interleukin-6. Nat Med. 1997; 3(3):287-292.

5. Neipel F, Albrecht JC, Fleckenstein B. Cell-homologous genes in the Kaposi's sarcoma-associated rhadinovirus human herpesvirus 8: determinants of its pathogenicity? J Virol. 1997;71(6):4187-4192.

6. Renne R, et al. Lytic growth of Kaposi's sarcomaassociated herpesvirus (human herpesvirus 8 ) in culture. Nat Med. 1996;2(3):342-346.

7. Schulz TF. Epidemiology of Kaposi's sarcomaassociated herpesvirus/human herpesvirus 8. Adv Cancer Res. 1999;76:121-160.

8. Cohen A, Wolf DG, Guttman-Yassky E, Sarid R. Kaposi's sarcoma-associated herpesvirus: clinical, diagnostic, and epidemiological aspects. Crit Rev Clin Lab Sci. 2005;42(2):101-153.

9. Malnati MS, Dagna L, Ponzoni M, Lusso P. Human herpesvirus 8 (HHV-8/KSHV) and hematologic malignancies. Rev Clin Exp Hematol. 2003;7(4):375-405.

10. Kaposi M. Idiopathisches multiples pigmentsarkom her haut. Arch Dermat Shypilol. 1872;4:265-273.

11. Regezi JA, et al. Oral Kaposi's sarcoma: a 10-year retrospective histopathologic study. J Oral Pathol Med. 1993;22(7):292-297.

12. Regezi JA, MacPhail LA, Daniels TE, DeSouza YG, Greenspan JS, Greenspan D. Human immunodeficiency virus-associated oral Kaposi's sarcoma. A heterogeneous cell population dominated by spindle-shaped endothelial cells. Am J Pathol. 1993; 143(1):240-249.

13. Herndier B, Ganem D. The biology of Kaposi's sarcoma. Cancer Treat Res. 2001;104:89-126.

14. Grayson W, Pantanowitz L. Histological variants of cutaneous Kaposi sarcoma. Diagn Pathol. 2008;3:31.

15. Hanahan D, Folkman J. Patterns and emerging mechanisms of the angiogenic switch during tumorigenesis. Cell. 1996;86(3):353-364.

16. Boshoff C, et al. Kaposi's sarcoma-associated herpesvirus infects endothelial and spindle cells. Nat
Med. 1995;1(12):1274-1278.

17. Staskus KA, et al. Kaposi's sarcoma-associated herpesvirus gene expression in endothelial (spindle) tumor cells. J Virol. 1997;71(1):715-719.

18. Ensoli B, Sturzl M. Kaposi's sarcoma: a result of the interplay among inflammatory cytokines, angiogenic factors and viral agents. Cytokine Growth Factor Rev. 1998;9(1):63-83.

19. Ensoli B, Sgadari C, Barillari G, Sirianni MC, Sturzl M, Monini P. Biology of Kaposi's sarcoma. Eur J Cancer. 2001;37(10):1251-1269.

20. Beckstead JH, Wood GS, Fletcher V. Evidence for the origin of Kaposi's sarcoma from lymphatic endothelium. Am J Pathol. 1985;119(2):294-300.

21. Weninger W, et al. Expression of vascular endothelial growth factor receptor- 3 and podoplanin suggests a lymphatic endothelial cell origin of Kaposi's sarcoma tumor cells. Lab Invest. 1999;79(2):243-251.

22. Skobe $M$, et al. Vascular endothelial growth factor-C (VEGF-C) and its receptors KDR and flt- 4 are expressed in AIDS-associated Kaposi's sarcoma. Invest Dermatol. 1999;113(6):1047-1053.

23. Marchio $S$, et al. Vascular endothelial growth factor- $\mathrm{C}$ stimulates the migration and proliferation of Kaposi's sarcoma cells. J Biol Chem. 1999; 274(39):27617-27622.

24. Wang HW, et al. Kaposi sarcoma herpesvirusinduced cellular reprogramming contributes to the lymphatic endothelial gene expression in Kaposi sarcoma. Nat Genet. 2004;36(7):687-693.

25. Hong YK, et al. Lymphatic reprogramming of blood vascular endothelium by Kaposi sarcoma-associated herpesvirus. Nat Genet. 2004;36(7):683-685.

26. Carroll PA, Brazeau E, Lagunoff M. Kaposi's sarcoma-associated herpesvirus infection of blood endothelial cells induces lymphatic differentiation. Virology. 2004;328(1):7-18.

27. Judde JG, et al. Monoclonality or oligoclonality of human herpesvirus 8 terminal repeat sequences in Kaposi's sarcoma and other diseases. J Natl Cancer Inst. 2000;92(9):729-736.

28. Duprez R, et al. Evidence for a multiclonal origin of multicentric advanced lesions of Kaposi sarcoma. J Natl Cancer Inst. 2007;99(14):1086-1094.

29. Rabkin C, et al. Monoclonal origin of multicentric Kaposi's sarcoma lesions. N Engl J Med. 1997; 336(14):988-993

30. Ensoli B, et al. AIDS-Kaposi's sarcoma-derived cells express cytokines with autocrine and paracrine growth effects. Science 1989;243(4888):223-226.

31. Salahuddin SZ, et al. Angiogenic properties of Kaposi's sarcoma-derived cells after long-term cul- ture in vitro. Science. 1988;242(4877):430-433.

32. Moore PS, Chang Y. Detection of herpesvirus-like DNA sequences in Kaposi's sarcoma in patients with and without HIV infection. $N$ Engl J Med. 1995;332(18):1181-1185.

33. Brooks JJ. Kaposi's sarcoma: a reversible hyperplasia. Lancet. 1986;2(8519):1309-1311.

34. Safai B. Kaposi's sarcoma: a review of the classical and epidemic forms. Ann N Y Acad Sci. 1984; 437:373-382.

35. Dezube BJ. Clinical presentation and natural history of AIDS--related Kaposi's sarcoma. Hematol Oncol Clin North Am. 1996;10(5):1023-1029.

36. Niedt GW, Prioleau PG. Kaposi's sarcoma occurring in a dermatome previously involved by herpes zoster. J Am Acad Dermatol. 1988;18(2 Pt 2):448-451.

37. Potouridou I, Katsambas A, Pantazi V, Armenaka M, Vareltzidis A, Stratigos J. Koebner phenomenon in classic Kaposi's sarcoma. Acta Derm Venereol. 1997;77(6):481.

38. French PD, Harris JR, Mercey DE. The Koebner phenomenon and AIDS-related Kaposi's sarcoma. Br J Dermatol. 1994;131(5):746-747.

39. Kirshner J, Staskus K, Haase A, Lagunoff M, Ganem D. The expression of the ORF 74 (G-protein coupled receptor) gene of Kaposi's sarcoma-associated herpesvirus: implications for KS pathogenesis. J Virol. 1999;73(7):6006-6014.

40. Cesarman E, Mesri EA, Gershengorn MC. Viral G protein-coupled receptor and Kaposi's sarcoma: a model of paracrine neoplasia? J Exp Med. 2000; 191(3):417-422.

41. Beral V, Peterman TA, Berkelman RL, Jaffe HW. Kaposi's sarcoma among persons with AIDS: a sexually transmitted infection? Lancet. 1990; 335(8682):123-128.

42. Dupin N, et al. Herpesvirus-like DNA sequences in patients with Mediterranean Kaposi's sarcoma. Lancet. 1995;345(8952):761-762.

43. Boshoff C, et al. Kaposi's-sarcoma-associated herpesvirus in HIV-negative Kaposi's sarcoma. Lancet. 1995;345(8956):1043-1044.

44. Collandre H, Ferris S, Grau O, Montagnier L, Blanchard A. Kaposi's sarcoma and new herpesvirus. Lancet. 1995;345(8956):1043.

45. Kedes DH, Operskalski E, Busch M, Kohn R, Flood J, Ganem D. The seroepidemiology of human herpesvirus 8 (Kaposi's sarcoma-associated herpesvirus): distribution of infection in KS risk groups and evidence for sexual transmission. Nat Med. 1996;2(8):918-924.

46. Gao SJ, et al. KSHV antibodies among Americans, Italians and Ugandans with and without Kaposi's 
sarcoma. Nat Med. 1996;2(8):925-928.

47. Simpson GR, et al. Prevalence of Kaposi's sarcoma associated herpesvirus infection measured by antibodies to recombinant capsid protein and latent immunofluorescence antigen. Lancet. 1996; 348(9035):1133-1138.

48. Moore PS, et al. Kaposi's sarcoma-associated herpesvirus infection prior to onset of Kaposi's sarcoma. AIDS. 1996;10(2):175-180.

49. Martin JN, Ganem DE, Osmond DH, Page-Shafer KA, Macrae D, Kedes DH. Sexual transmission and the natural history of human herpesvirus 8 infection. NEngl J Med. 1998;338(14):948-954.

50. Smith NA, et al. Serologic evidence of human herpesvirus 8 transmission by homosexual but not heterosexual sex. J Infect Dis. 1999;180(3):600-606.

51. Grulich AE, Beral V, Swerdlow AJ. Kaposi's sarcoma in England and Wales before the AIDS epidemic. Br J Cancer. 1992;66(6):1135-1137.

52. Geddes M, et al. Kaposi's sarcoma in Italy before and after the AIDS-epidemic. Br J Cancer. 1994; 69(2):333-336.

53. Hjalgrim H, et al. Epidemiology of Kaposi's sarcoma in the Nordic countries before the AIDS epidemic. BrJ Cancer. 1996;74(9):1499-1502.

54. Iscovich J, Boffetta P, Franceschi S, Azizi E, Sarid R. Classic kaposi sarcoma: epidemiology and risk factors. Cancer. 2000;88(3):500-517.

55. Portsmouth S, et al. A comparison of regimens based on non-nucleoside reverse transcriptase inhibitors or protease inhibitors in preventing Kaposi's sarcoma. AIDS. 2003;17(11):F17-F22.

56. Gates AE, Kaplan LD. AIDS malignancies in the era of highly active antiretroviral therapy. Oncology (Williston Park). 2002;16(5):657-665.

57. Lebbe $\mathrm{C}$, et al. Clinical and biological impact of antiretroviral therapy with protease inhibitors on HIVrelated Kaposi's sarcoma. AIDS. 1998;12(7):F45-F49.

58. Cattelan AM, et al. Acquired immunodeficiency syndrome-related Kaposi's sarcoma regression after highly active antiretroviral therapy: biologic correlates of clinical outcome. J Natl Cancer Inst Monogr. 2001;(28):44-49.

59. Gill J, et al. Prospective study of the effects of antiretroviral therapy on Kaposi sarcoma - associated herpesvirus infection in patients with and without Kaposi sarcoma. J Acquir Immune Defic Syndr. 2002; 31(4):384-390

60. Lebbé C, Legendre C, Francès C. Kaposi sarcoma in transplantation. Transplant Rev (Orlando). 2008; 22(4):252-261.

61. Harrington W Jr, et al. Activation of HHV-8 by HIV-1 tat. Lancet. 1997;349(9054):774-775.

62. Varthakavi V, Smith RM, Deng H, Sun R, Spearman P. Human immunodeficiency virus type- 1 activates lytic cycle replication of Kaposi's sarcoma-associated herpesvirus through induction of KSHV Rta. Virology. 2002;297(2):270-280.

63. Mercader M, Taddeo B, Panella JR, Chandran B, Nickoloff BJ, Foreman KE. Induction of HHV-8 lytic cycle replication by inflammatory cytokines produced by HIV-1-infected T cells. Am J Pathol. 2000;156(6):1961-1971.

64. Barillari G, Ensoli B. Angiogenic effects of extracellular human immunodeficiency virus type 1 Tat protein and its role in the pathogenesis of AIDSassociated Kaposi's sarcoma. Clin Microbiol Rev. 2002; 15(2):310-326.

65. Renne R, Lagunoff M, Zhong W, Ganem D. The size and conformation of Kaposi's sarcoma-associated herpesvirus (human herpesvirus 8) DNA in infected cells and virions. J Virol. 1996;70(11):8151-8154.

66. Lagunoff M, Ganem D. Organization of the termini of the genome of the Kaposi's sarcoma-associated herpesvirus (human herpesvirus 8). Virology. 1997; 236(1):147-154.

67. Ambroziak JA, et al. Herpes-like sequences in HIVinfected and uninfected Kaposi's sarcoma patients.
Science. 1995;268(5210):582-583.

68. Dupin N, et al. Distribution of human herpesvirus-8 latently infected cells in Kaposi's sarcoma, multicentric Castleman's disease, and primary effusion lymphoma. Proc Natl Acad Sci U S A. 1999; 96(8):4546-4551.

69. Parravicini C, et al. Differential viral protein expression in Kaposi's sarcoma-associated herpesvirusinfected diseases: Kaposi's sarcoma, primary effusion lymphoma, and multicentric Castleman's disease. Am J Pathol. 2000;156(3):743-749.

70. Blasig C, et al. Monocytes in Kaposi's sarcoma lesions are productively infected by human herpesvirus 8. J Virol. 1997;71(10):7963-7968.

71. Vieira J, O'Hearn P, Kimball L, Chandran B, Corey L. Activation of Kaposi's sarcoma-associated herpesvirus (human herpesvirus 8 ) lytic replication by human cytomegalovirus. J Virol. 2001;75(3):1378-1386.

72. Vieira J, O'Hearn PM. Use of the red fluorescent protein as a marker of Kaposi's sarcoma-associated herpesvirus lytic gene expression. Virology. 2004; 325(2):225-240.

73. Bechtel JT, Liang Y, Hvidding J, Ganem D. Host range of Kaposi's sarcoma-associated herpesvirus in cultured cells. J Virol. 2003;77(11):6474-6481.

74. Rappocciolo G, et al. Human herpesvirus 8 infects and replicates in primary cultures of activated B lymphocytes through DC-SIGN. J Virol. 2008; 82(10):4793-4806.

75. Kliche S, Kremmer E, Hammerschmidt W, Koszinowski U, Haas J. Persistent infection of Epstein-Barr viruspositive B lymphocytes by human herpesvirus 8 . JVirol. 1998;72(10):8143-8149.

76. Kieff E, Rickinson A. EBV and its replication. In: Knipe DM, Howley PM, eds. Fields' Virology. 5th ed. Philadelphia, PA: Lippincott, Williams and Wilkins; 2007:2603-2654.

77. Ciufo DM, et al. Spindle cell conversion by Kaposi's sarcoma-associated herpesvirus: formation of colonies and plaques with mixed lytic and latent gene expression in infected primary dermal microvascular endothelial cell cultures. J Virol. 2001; 75(12):5614-5626.

78. Grossman C, Podogrobskina S, Skobe M, Ganem D. Activation of NF- $\kappa$ B by the latent $v$-FLIP gene of KSHV is required for the spindle shape of virus-infected endothelial cells and contributes to their pro-inflammatory phenotype.J Virol. 2006;80(14):7179-7185.

79. Wang L, Damania B. Kaposi's sarcoma-associated herpesvirus confers a survival advantage to endothelial cells. Cancer Res. 2008;68(12):4640-4648.

80. Miller G, et al. Antibodies to butyrate-inducible antigens of Kaposi's sarcoma-associated herpesvirus in patients with HIV-1 infection. N EnglJ Med. 1996; 334(20):1292-1297.

81. Pauk J, et al. Mucosal shedding of human herpesvirus 8 in men. NEngl J Med. 2000;343(19):1369-1377.

82. Casper C, et al. Frequent and asymptomatic oropharyngeal shedding of human herpesvirus 8 among immunocompetent men. J Infect Dis. 2007; 195(1):30-36.

83. Duus KM, Lentchitsky V, Wagenaar T, Grose C, Webster-Cyriaque J. Wild-type Kaposi's sarcoma-associated herpesvirus isolated from the oropharynx of immunecompetent individuals has tropism for cultured oral epithelial cells. J Virol. 2004;78(8):4074-4084.

84. Katano H, Sato Y, Kurata T, Mori S, Sata T. Expression and localization of human herpesvirus 8encoded proteins in primary effusion lymphoma, Kaposi's sarcoma, and multicentric Castleman's disease. Virology. 2000;269(2):335-344.

85. Gao SJ, Boshoff C, Jayachandra S, Weiss RA, Chang Y, Moore PS. KSHV ORF K9 (vIRF) is an oncogene which inhibits the interferon signaling pathway. Oncogene. 1997;15(16):1979-1985.

86. Arvanitakis L, Geras-Raaka E, Varma A, Gershengorn MC, Cesarman E. Human herpesvirus KSHV encodes a constitutively active G-protein-coupled receptor linked to cell proliferation. Nature. 1997; 385(6614):347-350.

87. Bais C, et al. G-protein-coupled receptor of Kaposi's sarcoma-associated herpesvirus is a viral oncogene and angiogenesis activator. Nature. 1998; 391(6662):86-89.

88. Bais C, et al. Kaposi's sarcoma associated herpesvirus $G$ protein-coupled receptor immortalizes human endothelial cells by activation of the VEGF receptor-2/KDR. Cancer Cell. 2003;3(2):131-143.

89. Jenner RG, Albà MM, Boshoff C, Kellam P. Kaposi's sarcoma-associated herpesvirus latent and lytic gene expression as revealed by DNA arrays.J Virol. 2001;75(2):891-902.

90. Li M, et al. Kaposi's sarcoma-associated herpesvirus viral interferon regulatory factor. $J$ Virol. 1998;72(7):5433-5440.

91. Chiou CJ, et al. Patterns of gene expression and a transactivation function exhibited by the vGCR (ORF74) chemokine receptor protein of Kaposi's sarcoma-associated herpesvirus. J Virol. 2002; 76(7):3421-3439.

92. Dittmer D, Lagunoff M, Renne R, Staskus K, Haase A, Ganem D. A cluster of latently expressed genes in Kaposi's sarcoma-associated herpesvirus. J Virol. 1998;72(10):8309-8315.

93. Sarid R, Wiezorek JS, Moore PS, Chang Y. Characterization and cell cycle regulation of the major Kaposi's sarcoma-associated herpesvirus (Human herpesvirus 8) latent genes and their promoter. J Virol. 1999;73(2):1438-1446.

94. Talbot SJ, Weiss RA, Kellam P, Boshoff C. Transcriptional analysis of human herpesvirus- 8 open reading frames $71,72,73, \mathrm{~K} 14$, and 74 in a primary effusion lymphoma cell line. Virology. 1999;257(1):84-94.

95. Li H, Komatsu T, Dezube BJ, Kaye KM. The Kaposi's sarcoma-associated herpesvirus K12 transcript from a primary effusion lymphoma contains complex repeat elements, is spliced, and initiates from a novel promoter. J Virol. 2002;76(23):11880-11888.

96. Pearce M, Matsumura S, Wilson AC. Transcripts encoding K12, v-FLIP, v-cyclin, and the microRNA cluster of Kaposi's sarcoma-associated herpesvirus originate from a common promoter. J Virol. 2005; 79(22):14457-14464.

97. Cai X, Cullen BR. Transcriptional origin of Kaposi's sarcoma-associated herpesvirus microRNAs. J Virol. 2006;80(5):2234-2242.

98. Cai X, Lu S, Zhang Z, Gonzalez CM, Damania B, Cullen BR. Kaposi's sarcoma-associated herpesvirus expresses an array of viral microRNAs in latently infected cells. Proc Natl Acad Sci U S A. 2005; 102(15):5570-5575.

99. Pfeffer S, et al. Identification of microRNAs of the herpesvirus family. Nat Methods. 2005;2(4):269-276.

100.Samols MA, Hu J, Skalsky RL, Renne R. Cloning and identification of a microRNA cluster within the latency-associated region of Kaposi's sarcoma-associated herpesvirus. J Virol. 2005;79(14):9301-9305.

101. Grundhoff A, Sullivan CS, Ganem D. A combined computational and microarray-based approach identifies novel microRNAs encoded by human gamma-herpesviruses. RNA. 2006;12(5):733-750.

102.Umbach JL, Cullen BR. In-depth analysis of Kaposi's sarcoma-associated herpesvirus microRNA expression provides insights into the mammalian microRNA-processing machinery. J Virol. 2010; 84(2):695-703.

103. Fakhari FD, Dittmer DP. Charting latency transcripts in Kaposi's sarcoma-associated herpesvirus by whole-genome real-time quantitative PCR. J Virol. 2002;76(12):6213-6223.

104.Dittmer DP. Transcription profile of Kaposi's sarcoma-associated herpesvirus in primary Kaposi's sarcoma lesions as determined by real-time PCR arrays. Cancer Res. 2003;63(9):2010-2015.

105. Marshall V, et al. Conservation of virally encoded microRNAs in Kaposi sarcoma-associated herpesvi- 
rus in primary effusion lymphoma cell lines and in patients with Kaposi sarcoma or multicentric Castleman disease. J Infect Dis. 2007;195(5):645-659.

106. Rivas C, Thlick AE, Parravicini C, Moore PS, Chang Y. Kaposi's sarcoma-associated herpesvirus LANA2 is a B-cell-specific latent viral protein that inhibits p53. J Virol. 2001;75(1):429-438.

107. Ballestas ME, Chatis PA, Kaye KM. Efficient persistence of extrachromosomal KSHV DNA mediated by latency-associated nuclear antigen. Science. 1999;284(5414):641-644.

108. Ballestas ME, Kaye KM. Kaposi's sarcoma-associated herpesvirus latency-associated nuclear antigen 1 mediates episome persistence through cis-acting terminal repeat (TR) sequence and specifically binds TR DNA. J Virol. 2001;75(7):3250-3258.

109. Cotter MA 2nd, Robertson ES. The latency-associated nuclear antigen tethers the Kaposi's sarcoma-associated herpesvirus genome to host chromosomes in body cavity-based lymphoma cells. Virology. 1999;264(2):254-264

110. Cotter MA 2nd, Subramanian C, Robertson ES. The Kaposi's sarcoma-associated herpesvirus latencyassociated nuclear antigen binds to specific sequences at the left end of the viral genome through its carboxy-terminus. Virology. 2001;291(2):241-259.

111. Garber AC, Shu MA, Hu J, Renne R. DNA binding and modulation of gene expression by the latencyassociated nuclear antigen of Kaposi's sarcoma-associated herpesvirus. J Virol. 2001;75(17):7882-7892.

112. Garber AC, Hu J, Renne R. Latency-associated nuclear antigen (LANA) cooperatively binds to two sites within the terminal repeat, and both sites contribute to the ability of LANA to suppress transcription and to facilitate DNA replication.J Biol Chem. 2002; 277(30):27401-27411.

113. Barbera AJ, et al. The nucleosomal surface as a docking station for Kaposi's sarcoma herpesvirus LANA. Science. 2006;311(5762):856-861.

114. Viejo-Borbolla A, et al. Brd2/RING3 interacts with a chromatin-binding domain in the Kaposi's Sarcomaassociated herpesvirus latency-associated nuclear antigen 1 (LANA-1) that is required for multiple functions of LANA-1. J Virol. 2005;79(21):13618-13629.

115. Piolot T, Tramier M, Coppey M, Nicolas JC, Marecha V. Close but distinct regions of human herpesvirus 8 latency-associated nuclear antigen 1 are responsible for nuclear targeting and binding to human mitotic chromosomes. JVirol. 2001;75(8):3948-3959.

116. Grundhoff A, Ganem D. Inefficient establishment of KSHV latency suggests an additional role for continued lytic replication in Kaposi sarcoma pathogenesis. J Clin Invest. 2004;113(1):124-136.

117. Flamand L, Zeman RA, Bryant JL, Lunardi-Iskandar Y, Gallo RC. Absence of human herpesvirus 8 DNA sequences in neoplastic Kaposi's sarcoma cell lines. J Acquir Immune Defic Syndr Hum Retrovirol. 1996;13(2):194-197.

118. Aluigi MG, et al. KSHV sequences in biopsies and cultured spindle cells of epidemic, iatrogenic and Mediterranean forms of Kaposi's sarcoma. Res Virol. 1996;147(5):267-275.

119. Dictor M, Rambech E, Way D, Witte M, Bendsoe N Human herpesvirus 8 (Kaposi's sarcoma-associated herpesvirus) DNA in Kaposi's sarcoma lesions, AIDS Kaposi's sarcoma cell lines, endothelia Kaposi's sarcoma simulators, and the skin of immunosuppressed patients. Am J Pathol. 1996 148(6):2009-2016

120.Martin DF, Kuppermann BD, Wolitz RA, Palestine AG, Li H, Robinson CA. Oral ganciclovir for patients with cytomegalovirus retinitis treated with a ganciclovir implant. Roche Ganciclovir Study Group. NEngl J Med. 1999;340(14):1063-1070.

121. Friborg J Jr, Kong W, Hottiger MO, Nabel GJ. p53 inhibition by the LANA protein of KSHV protects against cell death. Nature. 1999;402(6764):889-894.

122. Radkov SA, Kellam P, Boshoff C. The latent nuclear antigen of Kaposi sarcoma-associated herpesvirus targets the retinoblastoma-E2F pathway and with the oncogene Hras transforms primary rat cells. Nat Med. 2000;6(10):1121-1127.

123. Fujimuro $M$, et al. A novel viral mechanism for dysregulation of beta-catenin in Kaposi's sarcomaassociated herpesvirus latency. Nat Med. 2003; 9(3):300-306.

124. Chang Y, et al. Cyclin encoded by KS herpesvirus. Nature. 1996;82(6590):410.

125. Verschuren EW, Jones N, Evan GI. The cell cycle and how it is steered by Kaposi's sarcoma-associated herpesvirus cyclin. J Gen Virol. 2004;85(Pt 6):1347-1361.

126.Swanton C, Mann DJ, Fleckenstein B, Neipel F, Peters G, Jones N. Herpes viral cyclin/Cdk6 complexes evade inhibition by CDK inhibitor proteins. Nature. 1997;390(6656):184-187.

127. Ellis M, et al. Degradation of p27(Kip) cdk inhibitor triggered by Kaposi's sarcoma virus cyclin-cdk6 complex. EMBO J. 1999;18(3):644-653

128. Mann DJ, Child ES, Swanton C, Laman H, Jones N. Modulation of p27(Kip1) levels by the cyclin encoded by Kaposi's sarcoma-associated herpesvirus. EMBO J. 1999;18(3):654-663.

129. Ojala PM, et al. Kaposi's sarcoma-associated herpesvirus-encoded $\mathrm{v}$-cyclin triggers apoptosis in cells with high levels of cyclin-dependent kinase 6 . Cancer Res. 1999;59(19):4984-4989.

130. Koopal S, et al. Viral oncogene-induced DNA damage response is activated in Kaposi sarcoma tumorigenesis. PLoS Pathog. 2007;3(9):1348-13460.

131. Thome M, et al. Viral FLICE-inhibitory proteins (FLIPs) prevent apoptosis induced by death receptors. Nature. 1997;386(6624):517-521.

132.Djerbi M, Screpanti V, Catrina AI, Bogen B, Biberfeld $\mathrm{P}$, Grandien A. The inhibitor of death receptor signaling, FLICE-inhibitory protein defines a new class of tumor progression factors. J Exp Med. 1999;190(7):1025-1032.

133. Belanger C, et al. Human herpesvirus 8 viral FLICEinhibitory protein inhibits Fas-mediated apoptosis through binding and prevention of procaspase- 8 maturation. J Hum Virol. 2001;4(2):62-73.

134. Chugh $\mathrm{P}$, et al. Constitutive NF-kappaB activation, normal Fas-induced apoptosis, and increased incidence of lymphoma in human herpes virus 8 K13 transgenic mice. Proc Natl Acad Sci U S A. 2005; 102(36):12885-12890.

135.Guasparri I, Keller SA, Cesarman E. KSHV vFLIP is essential for the survival of infected lymphoma cells. J Exp Med. 2004;199(7):993-1003.

136. Godfrey A, Anderson J, Papanastasiou A, Takeuchi $\mathrm{Y}$, Boshoff C. Inhibiting primary effusion lymphoma by lentiviral vectors encoding short hairpin RNA. Blood. 2005;105(6):2510-2518.

137. Chaudhary PM, Jasmin A, Eby MT, Hood L. Modulation of the NF-kappa B pathway by virally encoded death effector domains-containing proteins. Oncogene. 1999;18(42):5738-5746.

138. Matta H, Chaudhary PM. Activation of alternative NF-kappa B pathway by human herpes virus 8-encoded Fas-associated death domain-like IL-1 beta-converting enzyme inhibitory protein (vFLIP). Proc Natl Acad Sci U S A. 2004;101(25):9399-9404.

139.Liu L, Eby MT, Rathore N, Sinha SK, Kumar A Chaudhary PM. The human herpes virus 8-encoded viral FLICE inhibitory protein physically associates with and persistently activates the IkB kinase complex. J Biol Chem. 2002;277(16):13745-13751.

140 . Field N, et al. KSHV vFLIP binds to IKK-gamma to activate IKK. J Cell Sci. 2003;116(pt 18):3721-3728.

141. Bagnéris C, et al. Crystal structure of a vFlipIKKgamma complex: insights into viral activation of the IKK signalosome. Mol Cell. 2008;30(5):620-631.

142.Efklidou S, Bailey R, Field N, Noursadeghi M, Collins MK. vFLIP from KSHV inhibits anoikis of primary endothelial cells. J Cell Sci. 2008; 121(Pt 4):450-457.
143. Thurau M, et al. Viral inhibitor of apoptosis vFLIP/ $\mathrm{K} 13$ protects endothelial cells against superoxideinduced cell death. J Virol. 2009;83(2):598-611.

144. Matta H, et al. Induction of spindle cell morphology in human vascular endothelial cells by human herpesvirus 8-encoded viral FLICE inhibitory protein K13. Oncogene. 2007;26(11):1656-1660.

145. Brown HJ, Song MJ, Deng H, Wu TT, Cheng G, Sun R. NF-kappaB inhibits gammaherpesvirus lytic replication. J Virol. 2003;77(15):8532-8540.

146. Grossmann C, Ganem D. Effects of NFKB activation on KSHV latency and lytic reactivation are complex and context-dependent. Virology. 2008;375(1):94-102.

147. Sadler R, et al. A complex translational program generates multiple novel proteins from the latently expressed kaposin (K12) locus of Kaposi's sarcomaassociated herpesvirus. J Virol. 1999;73(7):5722-5730.

148. Muralidhar S, et al. Identification of kaposin (open reading frame K12) as a human herpesvirus 8 (Kaposi's sarcoma associated herpesvirus) transforming gene. J Virol. 1998;72(6):4980-4988.

149. Kliche S, et al. Signaling by human herpesvirus 8 kaposin A through direct membrane recruitment of cytohesin-1. Mol Cell. 2007;7(4):833-843.

150.Gillingham AK, Munro S. The small G proteins of the Arf family and their regulators. Annu Rev Cell Dev Biol. 2007;23:579-611.

151. McCormick C, Ganem D. The kaposin B protein of KSHV activates the $\mathrm{p} 38 / \mathrm{MK} 2$ pathway and stabilizes cytokine mRNAs. Science. 2005;307(5710):739-741.

152. Bellare P, Ganem D. Regulation of KSHV lytic switch protein expression by a virus-encoded microRNA: an evolutionary adaptation that fine-tunes lytic reactivation. Cell Host Microbe. 2009;6(6):570-575.

153.Ziegelbauer J, Sullivan C, Ganem D. Serial arraybased expression screens identify BCLAF/Btf as a target of multiple KSHV-encoded miRNAs. Nature Genetics. 2009;41(1):130-134.

154. Samols MA, et al. Identification of cellular genes targeted by KSHV-encoded microRNAs. PLoS Pathog. 2007;3(5):e65

155.Skalsky RL, et al. Kaposi's sarcoma-associated herpesvirus encodes an ortholog of miR-155.J Virol. 2007; 81(23):12836-12845

156. Gottwein E, et al. A viral microRNA functions as an orthologue of cellular miR-155. Nature. 2007; 450(7172):1096-1099.

157. Hansen A, et al. KSHV-encoded miRNAs target MAF to induce endothelial cell reprogramming. Genes Dev. 2010;24(2):195-205.

158. Chandriani S, Ganem D. Array-based transcript profiling and limiting-dilution RT-PCR analysis identify additional latent genes in KSHV.J Virol. In press.

159. Lee BS, Lee SH, Feng P, Chang H, Cho NH, Jung JU. Characterization of the Kaposi's sarcoma-associated herpesvirus K1 signalosome. J Virol. 2005; 79(19):12173-12184.

160. Wang L, Dittmer DP, Tomlinson CC, Fakhari FD, Damania B. Immortalization of primary endothelial cells by the K1 protein of Kaposi's sarcoma-associated herpesvirus. Cancer Res. 2006;66(7):3658-3666.

161. Molden J, Chang Y, You Y, Moore PS, Goldsmith MA. A Kaposi's sarcoma-associated herpesvirusencoded cytokine homolog (vIL-6) activates signaling through the shared gp130 receptor subunit. J Biol Chem. 1997;272(31):19625-19631.

162. Aoki Y, et al. Angiogenesis and hematopoiesis induced by Kaposi's sarcoma-associated herpesvirus-encoded interleukin-6. Blood. 1999;93(12):4034-4043.

163. Vart RJ, et al. Kaposi's sarcoma-associated herpesvirus-encoded interleukin-6 and G-protein-coupled receptor regulate angiopoietin-2 expression in lymphatic endothelial cells. Cancer Res. 2007; 67(9):4042-4051.

164. Moore PS, Boshoff C, Weiss RA, Chang Y. Molecular mimicry of human cytokine and cytokine response pathway genes by KSHV. Science. 1996; 274(5293):1739-1744. 
165.Sozzani S, et al. The viral chemokine macrophage inflammatory protein-II is a selective Th2 chemoattractant. Blood. 1998;92(11):4036-4039.

166. Stine JT, et al. KSHV-encoded CC chemokine vMIPIII is a CCR4 agonist, stimulates angiogenesis, and selectively chemoattracts TH2 cells. Blood. 2000; 95(4):1151-1157.

167. Nicholas J. Human gammaherpesvirus cytokines and chemokine receptors. IInterferon Cytokine Res. 2005;25(7):373-383.

168. Haque NS, Fallon JT, Taubman MB, Harpel PC. The chemokine receptor CCR8 mediates human endothelial cell chemotaxis induced by I-309 and Kaposi sarcoma herpesvirus-encoded vMIP-I and by lipoprotein(a)-stimulated endothelial cell conditioned medium. Blood. 2001;97(1):39-45

169.Liu C, Okruzhnov Y, Li H, Nicholas J. Human herpesvirus 8 (HHV-8)-encoded cytokines induce expression of and autocrine signaling by vascular endothelial growth factor (VEGF) in HHV-8infected primary-effusion lymphoma cell lines and mediate VEGF-independent antiapoptotic effects. JVirol. 2001;75(22):10933-10940.

170.Boshoff C, et al. Angiogenic and HIV-inhibitory functions of KSHV-encoded chemokines. Science. 1997;278(5336):290-294.

171. Choi YB, Nicholas J. Autocrine and paracrine promotion of cell survival and virus replication by human herpesvirus 8 chemokines. J Virol. 2008; 82(13):6501-6513

172. Sodhi A, et al. The Kaposi's sarcoma-associated herpes virus $G$ protein-coupled receptor up-regulates vascular endothelial growth factor expression and secretion through mitogen-activated protein kinase and $\mathrm{p} 38$ pathways acting on hypoxia-inducible factor 1alpha. Cancer Res. 2000;60(17):4873-4880.

173. Sadagopan S, et al. Kaposi's sarcoma-associated herpesvirus upregulates angiogenin during infection of human dermal microvascular endothelial cells, which induces 45S rRNA synthesis, antiapoptosis, cell proliferation, migration, and angiogenesis. J Virol. 2009;83(7):3342-3364.

174. Ye FC, et al. Kaposi's sarcoma-associated herpesvirus promotes angiogenesis by inducing angiopoietin-2 expression via AP-1 and Ets1. J Virol. 2007; 81(8):3980-3991.

175. Chandriani S, Ganem D. Host transcript accumulation during lytic KSHV infection reveals several classes of host responses. PLoS ONE. 2007;2(8):e811.

176. Bowser BS, Morris S, Song MJ, Sun R, Damania B. Characterization of Kaposi's sarcoma-associated herpesvirus (KSHV) K1 promoter activation by Rta. Virology. 2006;348(2):309-327.

177. Wang L, et al. The Kaposi's sarcoma-associated herpesvirus (KSHV/HHV8) K1 protein induces expression of angiogenic and invasion factors. Cancer Res. 2004;64(8):2774-2781.

178. Wang L, Dittmer DP, Tomlinson CC, Fakhari FD, Damania B. Immortalization of primary endothelial cells by the K1 protein of Kaposi's sarcoma-associated herpesvirus. Cancer Res. 2006;66(7):3658-3666.

179. Brinkmann MM, Pietrek M, Dittrich-Breiholz O, Kracht M, Schulz TF. Modulation of host gene expression by the K15 protein of Kaposi's sarcomaassociated herpesvirus. J Virol. 2007;81(1):42-58.

180 . Konrad A, et al. A systems biology approach to identify the combination effects of human herpesvirus 8 genes on NF-kappaB activation. J Virol. 2009; 83(6):2563-2574.

181.Glaunsinger B, Ganem D. Lytic KSHV infection inhibits host gene expression by accelerating global mRNA turnover. Mol Cell. 2004;13(5):713-723.

182. Mutlu AD, et al. In vivo-restricted and reversible malignancy induced by human herpesvirus- 8 KSHV: a cell and animal model of virally induced Kaposi's sarcoma. Cancer Cell. 2007;11(3):245-258.

183.Leidner RS, Aboulafia DM. Recrudescent Kaposi's sarcoma after initiation of HAART: a manifestation of immune reconstitution syndrome. AIDS Patient Care STDS. 2005;19(10):635-644.

184. Bower $\mathrm{M}$, et al. Immune reconstitution inflammatory syndrome associated with Kaposi's sarcoma. J Clin Oncol. 2005;23(22):5224-5228.

185. Connick E, Kane MA, White IE, Ryder J, Campbell TB. Immune reconstitution inflammatory syndrome associated with Kaposi sarcoma during potent antiretroviral therapy. Clin Infect Dis. 2004; 39(12):1852-1855

186. Feller L, Anagnostopoulos C, Wood NH, Bouckaert M, Raubenheimer EJ, Lemmer J. Human immunodeficiency virus-associated Kaposi sarcoma as an immune reconstitution inflammatory syndrome: a literature review and case report. J Periodontol. 2008; $79(2): 362-368$.

187. Stallone G, et al. Sirolimus for Kaposi's sarcoma in renal-transplant recipients. $N$ Engl J Med. 2005; 352(13):1371-1373

188. Hay N, Sonenberg N. Upstream and downstream of mTOR. Genes Dev. 2004;18(16):1926-1945.

189. Gutiérrez-Dalmau A, et al. Efficacy of conversion to sirolimus in posttransplantation Kaposi's sarcoma. Transplant Proc. 2005;37(9):3836-3838.

190.Lebbé C, et al. Sirolimus conversion for patients with posttransplant Kaposi's sarcoma. Am J Transplant. 2006;6(9):2164-2168.

191. Sin SH, et al. Rapamycin is efficacious against primary effusion lymphoma (PEL) cell lines in vivo by inhibiting autocrine signaling. Blood. 2007; 109(5):2165-2173.

192. Morris VA, Punjabi AS, Lagunoff M. Activation of Akt through gp130 receptor signaling is required for Kaposi's sarcoma-associated herpesvirus-induced lymphatic reprogramming of endothelial cells. J Virol. 2008;82(17):8771-8779.

193. Moore PS, et al. Primary characterization of a herpesvirus agent associated with Kaposi's sarcoma. J Virol. 1996;70(1):549-558. 